\title{
3-D TRANSIENT COUPLED SIMULATION OF SUPERPHENIX WITH PARCS/ATHLET
}

\author{
Jeremy Bousquet, Romain Henry, and Armin Seubert
}

Gesellschaft für Anlagen- und Reaktorsicherheit (GRS) gGmbH

Boltzmannstr. 14, 85748 Garching, Germany

jeremy.bousquet@grs.de,romain.henry@grs.de, armin.seubert@grs.de

\begin{abstract}
Most safety criteria for Sodium cooled Fast Reactors (SFR) are local core parameters. Thus, application of 3-D neutron kinetic and thermal-hydraulic coupled codes including detailed modelling of core expansion effects is mandatory for best estimate evaluations of safety margins. A recently published benchmark based on measurements performed at the Superphénix (SPX) reactor offers the opportunity to validate codes and methods for SFR safety assessment. In this paper, the SPX core is modelled in ATHLET and PARCS. Explicit models for axial and radial core expansion effects for 3-D coupled calculations were recently implemented in PARCS. In ATHLET, axial thermal expansion of structures (strongback, vessel, control rod drive line) influencing the relative position of the control rod in the active core is modelled. The newly implemented models are tested on a transient initiated by a reactivity insertion of $-50 \mathrm{pcm}$. A point kinetic simulation is also performed to compare with the 3D solution. Both ATHLET-point kinetic model and ATHLET-PARCS simulations deliver similar power responses during the transient but with an offset. By analysing the different feedbacks in the point kinetic model, it can be concluded that models of expansion of the different structures are well implemented. In the future further analysis of different transients of the benchmark are planned.
\end{abstract}

KEYWORDS: SFR, SPX, Thermal expansion, PARCS, ATHLET

\section{INTRODUCTION}

Superphénix (SPX) is a 2990 MW Sodium cooled Fast Reactor which was operated between 1985 and 1997 in Creys-Malville (France) [1]. During that time, data on the physical properties of the core such as reaction rate distributions and feedback coefficients were measured and can be used in order to validate methods and codes for SFR simulations. In the framework of the ongoing ESFRSMART EU project [2], a benchmark based on the Superphénix reactor core was recently proposed [3] to take advantage of these experimental results. Since most of the safety criteria for SFR are local core parameters, application of 3-D neutron kinetic and thermal-hydraulic coupled codes including detailed modelling of core expansion effects is mandatory for best estimate evaluations of safety margins. This is accounted for by appropriate neutron kinetics model extensions in the diffusion code PARCS [4] for the 3-D simulation of axial and radial thermal expansion effects in connection with an appropriate parametrization of the few-group cross-section libraries $[5,6]$. 
In the first part of the benchmark, static calculations were performed. A full core model was developed for the Monte-Carlo code Serpent [7] and for PARCS. Integral parameters, feedback coefficients and power density distributions were evaluated by GRS [8]. Good agreement was obtained with benchmark reference calculations and measurements. The second part of the benchmark proposes to analyse six different transients. This paper focuses on the first scenario (so called MOFC1): the transient begins at $692 \mathrm{MW}$ ( $23 \%$ of the nominal power) with a reactivity insertion of $-50 \mathrm{pcm}$ in $2 \mathrm{~s}$ (control rod insertion).

First, numerical models and methods are presented and described, while emphasis is given on radial expansion models recently implemented in PARCS and ATHLET [9]. Furthermore, the transient scenario and its initial conditions are defined. Predictions of the coupled model are shown and discussed. Finally, conclusions are drawn and discussion on futures development are presented.

\section{NUMERICAL MODELS AND METHODS}

\subsection{Neutronics}

For coupled 3-D neutron-kinetic/thermal-hydraulic simulation, the deterministic code PARCS [4] was used to model the core of SPX. PARCS is a 3-D reactor core simulator, developed at the University of Michigan, which solves the steady-state and time-dependent multi-group neutron diffusion equation in Cartesian or hexagonal geometries. Furthermore, since major feedback effects are due to thermal expansion of the materials, PARCS has been recently extended to model explicitly radial core expansion [6].

SPX is modelled in PARCS as a full core using one hexagonal radial node (cold pitch $17.9 \mathrm{~cm}$ ) per subassembly (in total 919 hexagonal radial nodes) and 53 axial meshes (cold height $4.029 \mathrm{~m}$ ). The axial mesh size varies from $2 \mathrm{~cm}$ to $16 \mathrm{~cm}$ due to the axial heterogeneity and to account for the control and safety rods' initial positions. The integrated TPEN solver is used. For transient calculations, delayed neutron data in 8 precursor time groups have been used. They were calculated with a whole core Serpent simulation of the SPX core at nominal conditions using the JEFF-3.1.1 library.

Cross-sections were generated with the Monte-Carlo code Serpent [7]: fuel subassemblies are modelled in full extent in an infinite 3-D lattice while non-fuel subassembly types are modelled in 2-D surrounded by 6 neighbouring half fuel subassemblies with reflective boundary condi-

tions. Each Serpent calculation is performed with 4,000 active cycles (and 100 inactive cycles) of $2,000,000$ source neutrons to obtain an uncertainty on the multiplication factor less than $2.5 \mathrm{pcm}$ for each calculation. All the Serpent input and the cross-section parametrization were prepared with KMACS [10] which is the core simulator developed at GRS. Cross-section libraries have collapsed into a 12-energy group structure (see Table 1) which is based on the 8-energy group structure suggested in [11] and extended by additional group subdivisions. The cross-section libraries were parametrized with respect to fuel temperature $(300 \mathrm{~K}, 600 \mathrm{~K}, 900 \mathrm{~K}, 1200 \mathrm{~K})$, coolant density $\left(941 \mathrm{~kg} / \mathrm{m}^{3}, 874 \mathrm{~kg} / \mathrm{m}^{3}, 805 \mathrm{~kg} / \mathrm{m}^{3}\right)$ and subassembly lattice pitch $(17.90 \mathrm{~cm}, 17.98 \mathrm{~cm}$, $18.05 \mathrm{~cm}$ ). All calculations are performed with the JEFF-3.1.1 continuous energy library. More detailed information on the static neutronics calculations can be found in [8]. 
Table 1: 12-energy group structure

\begin{tabular}{|c|c|c|c|c|c|c|c|}
\hline $\begin{array}{c}\text { Group } \\
\mathrm{nb}\end{array}$ & $\begin{array}{c}\text { Upper enegy } \\
\text { lim. }(\mathrm{MeV})\end{array}$ & $\begin{array}{c}\text { Group } \\
\mathrm{nb}\end{array}$ & $\begin{array}{c}\text { Upper enegy } \\
\text { lim. }(\mathrm{MeV})\end{array}$ & $\begin{array}{c}\text { Group } \\
\mathrm{nb}\end{array}$ & $\begin{array}{c}\text { Upper enegy } \\
\text { lim. }(\mathrm{MeV})\end{array}$ & $\begin{array}{c}\text { Group } \\
\mathrm{nb}\end{array}$ & $\begin{array}{c}\text { Upper enegy } \\
\text { lim. }(\mathrm{MeV})\end{array}$ \\
\hline 1 & $2.00 \mathrm{E}+01$ & 4 & $8.21 \mathrm{E}-01$ & 7 & $4.09 \mathrm{E}-02$ & 10 & $2.03 \mathrm{E}-03$ \\
\hline 2 & $6.07 \mathrm{E}+00$ & 5 & $3.02 \mathrm{E}-01$ & 8 & $1.50 \mathrm{E}-02$ & 11 & $7.49 \mathrm{E}-04$ \\
\hline 3 & $2.23 \mathrm{E}+00$ & 6 & $1.11 \mathrm{E}-01$ & 9 & $5.53 \mathrm{E}-03$ & 12 & $1.49 \mathrm{E}-04$ \\
\hline
\end{tabular}

\subsection{Thermal-Hydraulic}

ATHLET (Analysis of THermal-hydraulics of LEaks and Transients) [9] is being developed by GRS within the $\mathrm{AC}^{2}$ code package [12] for the safety assessment of the whole spectrum of leaks and transients in light water reactors (PWRs and BWRs) without core degradation, small modular reactors (SMR) as well as in GEN-IV reactors with helium or liquid metal $(\mathrm{Na}, \mathrm{Pb}, \mathrm{LBE})$ coolants.

The thermal-hydraulic representation of the SPX core is a parallel-channel open core model. Every fuel subassembly (Inner Core IC and Outer Core OC), Radial Blanket (RB) is modelled as an individual channel (see Figure 1) while all non-fuel e.g. Control Rods, Radial Reflectors are lumped into a single channel without heat structure (called NOFUEL in Figure 1). For the coupled PARCS/ATHLET simulation, every fuel assembly and radial blanket is mapped 1-by-1 to their corresponding thermal-hydraulic channels in ATHLET. Each thermal-hydraulic channel is connected to the lower plenum at the bottom and to the upper plenum at the top. The inlet coolant mass flow and temperature are provided as boundary condition in the lower plenum volume. In the benchmark it is proposed to model the vessel as one independent open pipe whose inlet coolant mass flow and temperature boundary conditions are similar to the core boundary conditions but with a 360 s delay.

\subsection{Thermal Expansion}

Unlike in PWR, thermal expansion effects are very important feedback in SFR and must be considered. Six thermal expansion effects are identified:

- Fuel expansion: when the fuel temperature increases, the dimensions of the fuel rod expand along with simultaneous decrease of the fuel density. In addition, the axial expansion of the fuel influences the relative position of the control rods in the active core.

- Cladding expansion: when the cladding temperature increases, the dimensions of the cladding expand along with simultaneous decrease of the cladding density.

- Diagrid expansion: the diagrid is the structure below the core maintaining the fuel assemblies pitch. When the diagrid expands due to an inlet temperature increase, the fuel assembly pitch increases.

- Strongback expansion: the strongback is the structure supporting the diagrid on the vessel. The axial expansion of the strongback influences the relative position of the control rod in the active core.

- Vessel expansion: the axial expansion of the vessel influences the relative position of the control rod in the active core. 


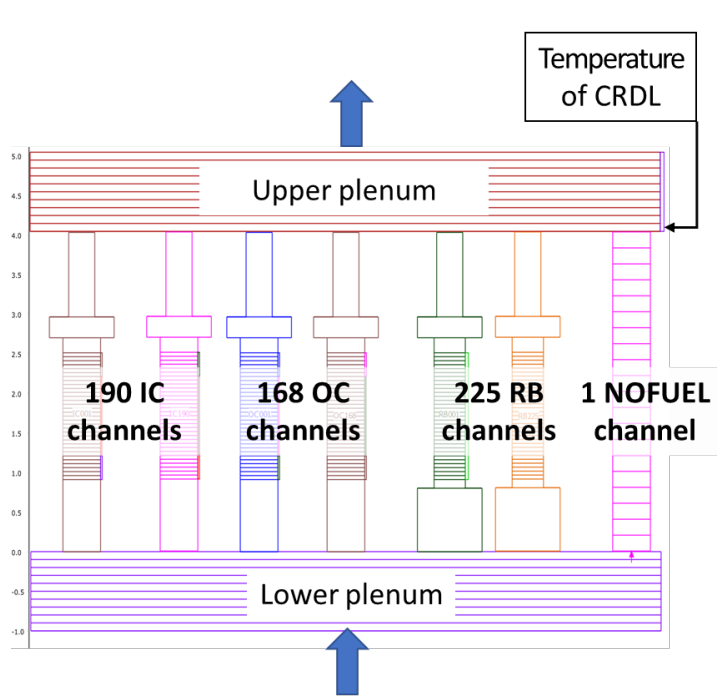

$(T s, M s)=f(t)$

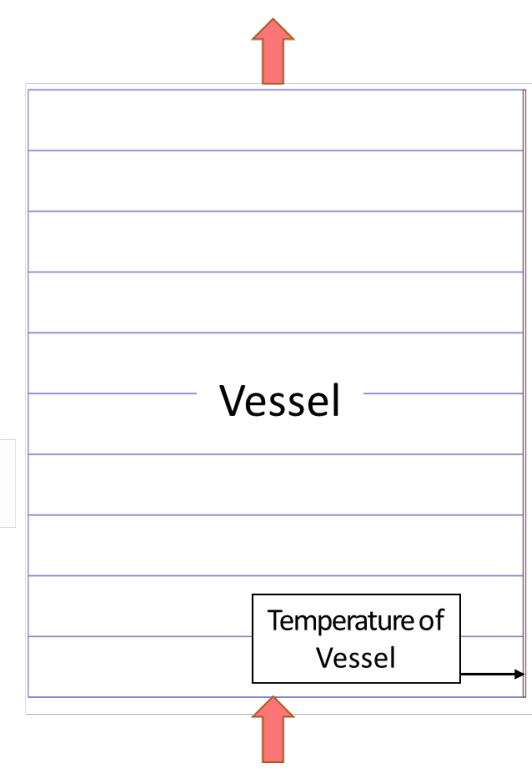

$(T s, M s)=f(t+360 s)$

Figure 1: Thermal-hydraulic open core ATHLET model of SPX

- Control Rod Drive Lines (CRDL) expansion: they are the steel lines maintaining the control rod above the core. Their axial expansion influences the relative position of the control rod in the active core.

In this work, the following expansion effects are considered: the radial expansion effect of the diagrid and the axial thermal expansion of the structures influencing the relative position of the control rod in the active core i.e. the fuel rod, the strongback, the vessel and the CRDL thermal expansions. The changes of the density of the fuel rod and the cladding are not taken into account in this study. It should be noted that at this stage, temperature-driven geometric deformations are not yet considered in the thermal-hydraulic model.

The radial expansion model, implemented in PARCS, is based on an explicit 3-D model which uses fixed neutronic reactor core nodalizations. Changes of the subassembly pitch are modelled by a radial coordinate transform of the neutron diffusion equation (see [6] and [5]). In the benchmark, the diagrid temperature is assumed equal to the inlet temperature.

The axial thermal expansion is calculated for each structure i.e. the fuel rod, the strongback, the vessel and the CRDL. ATHLET solves the heat conduction equation for the fuel rod, the vessel, and the CRDL. In the benchmark, it is proposed to take the temperature of the strongback equal to the inlet temperature with a delay of $100 \mathrm{~s}$. Recent developments in ATHLET allows the code to be controlled by a Python-controller. It was developed to simulate the expansion of each structure on the fly according to the temperature calculated by ATHLET. The new relative position of the control rods in the active zone is then evaluated and transferred to PARCS at each time step. Figure 2 represents the calculation process and the data exchange between different codes during 
one time step.

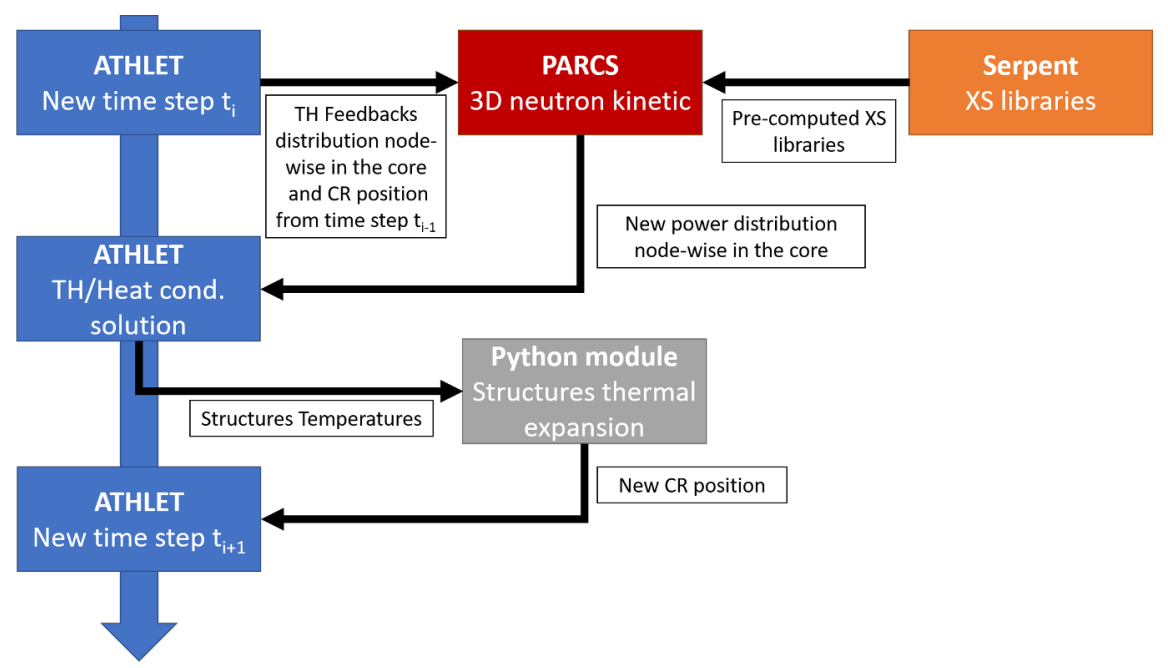

Figure 2: Diagram of calculation process during one time step.

For the sake of comparison, the same transient was run with ATHLET with a point kinetic model. All the needed parameters were provided in the benchmark and are presented in Table 2.

Table 2: Feedback coefficients used in the point kinetic model

\begin{tabular}{|c|c|c|c|c|c|}
\hline $\begin{array}{c}\text { Doppler } \\
\text { constant }[\mathrm{pcm}]\end{array}$ & $\begin{array}{c}\text { Sodium density } \\
{[\mathrm{pcm} /(\mathrm{kg} / \mathrm{m} 3)]}\end{array}$ & $\begin{array}{c}\text { Fuel exp. } \\
{[\mathrm{pcm} / \mathrm{K}]}\end{array}$ & $\begin{array}{c}\text { Cladding exp. } \\
{[\mathrm{pcm} / \mathrm{K}]}\end{array}$ & $\begin{array}{c}\text { Diagrid exp. } \\
{[\mathrm{pcm} / \mathrm{K}]}\end{array}$ & $\begin{array}{c}\text { Prompt neutron } \\
\text { lifetime }[\mathrm{s}]\end{array}$ \\
\hline-1115 & -0.992 & -0.192 & 0.050 & -0.992 & $4.9400 \mathrm{E}-07$ \\
\hline
\end{tabular}

\section{COUPLED SIMULATION}

\subsection{MOFC1 Transient Scenario}

In the selected scenario, the system is initially in a steady-state at $692 \mathrm{MW}(23 \%$ of the nominal power) with an inlet coolant flowrate of $6500 \mathrm{~kg} / \mathrm{s}$ and temperature of $384.9^{\circ} \mathrm{C}$. The control rods are initially $40 \mathrm{~cm}$ inserted in the core with a differential worth of $120.9 \mathrm{pcm} / \mathrm{cm}$. The transient starts at $50 \mathrm{~s}$ by inserting $-50 \mathrm{pcm}$ of reactivity in $2 \mathrm{~s}$ which is equivalent to a control rod insertion of $0.415 \mathrm{~cm}$. The inlet temperature is also decreasing and described in Figure 3 (it is equal to the diagrid temperature, blue curve).

\subsection{MOCF1 Transient Results}

Figure 3 presents the temperatures of the diagrid, strongback and the vessel (which are similar in both simulations). Figure 4 represents the power calculated by ATHLET with the point kinetic model and ATHLET-PARCS. In [13], the same transient was calculated with the thermal-hydraulic 
code RELAP with a point-kinetic model and the measured values are also provided. It can be observed that the power evolutions calculated by ATHLET with the point kinetic model and ATHLET with PARCS are similar to each other but with an offset of about $10 \mathrm{MW}$ to $20 \mathrm{MW}$. After the insertion of the control rods, the power decreases from $692 \mathrm{MW}$ to $606 \mathrm{MW}$ and from $692 \mathrm{MW}$ to $588 \mathrm{MW}$ in $5 \mathrm{~s}$ for the ATHLET-PARCS model and the ATHLET-point kinetic model, respectively. Then, the power increases from $55 \mathrm{~s}$ to $70 \mathrm{~s}$ mainly due to the Doppler effect and the control rod withdrawn (thermal contraction). From 70 s to 200 s, the power slowly decreases. From 200 s, the power slowly increases until $800 \mathrm{~s}$ and fluctuates around a stabilized power. ATHLET with point kinetic model fails to predict the measured power evolution while ATHLET with PARCS yields a good approximation of the power evolution until $400 \mathrm{~s}$. In contrast, the RELAP model calculates a very good approximation of the power evolution from $400 \mathrm{~s}$ to the end of the simulation. The analysis of the different reactivity components from the point kinetics model (not available in the 3-D model where all the effects are directly taken into account in the cross-sections), displayed in Figure 5, can help understand the power response. During the first $10 \mathrm{~s}$ of the transient, the Doppler effect, the fuel rod expansion effect, CRDL expansion effect are increasing the reactivity while the sodium density effect is decreasing it. This behaviour is expected and seems to confirm that the fuel rod and the CRDL expansions are well implemented in ATHLET. Moreover, the diagrid expansion effect and the strongback expansion effect appear at $200 \mathrm{~s}$ and $300 \mathrm{~s}$, respectively, as expected from the delay applied on the temperature boundary condition. The effect of the vessel expansion appears at $600 \mathrm{~s}$ which is consistent with its temperature (see Figure 3). After approximately $800 \mathrm{~s}$, the sum of all reactivity contributions compensates each other, and the power stabilizes. Further investigation to explain the discrepancy between the two models and the measurement are planned for the near future.

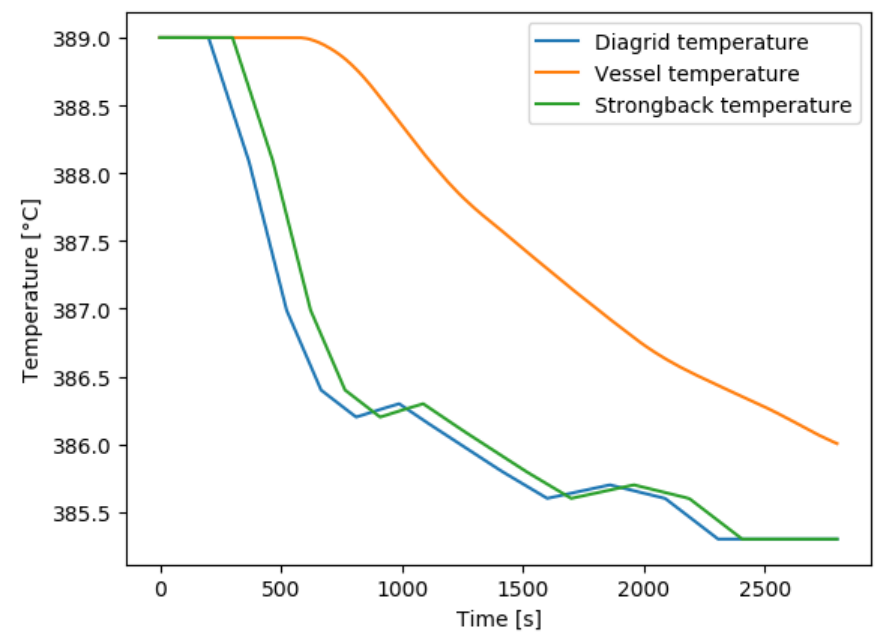

Figure 3: Temperature of Diagrid (Inlet), Strongback and Vessel during the MOCF1 transient 

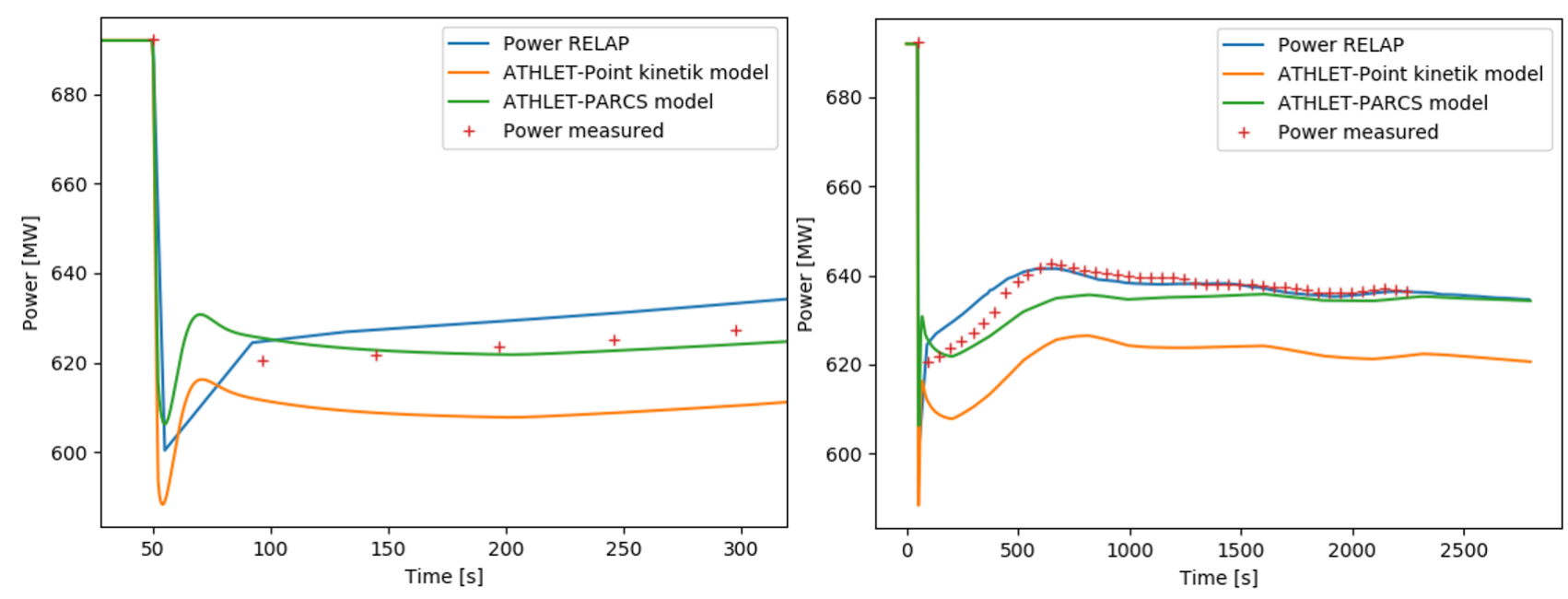

Figure 4: Power calculated by ATHLET-point kinetic, ATHLET-PARCS and by RELAP and measured power during the MOCF1 transient. Values from RELAP and measurements from [13]. Left side: zoom on the beginning of the transient.
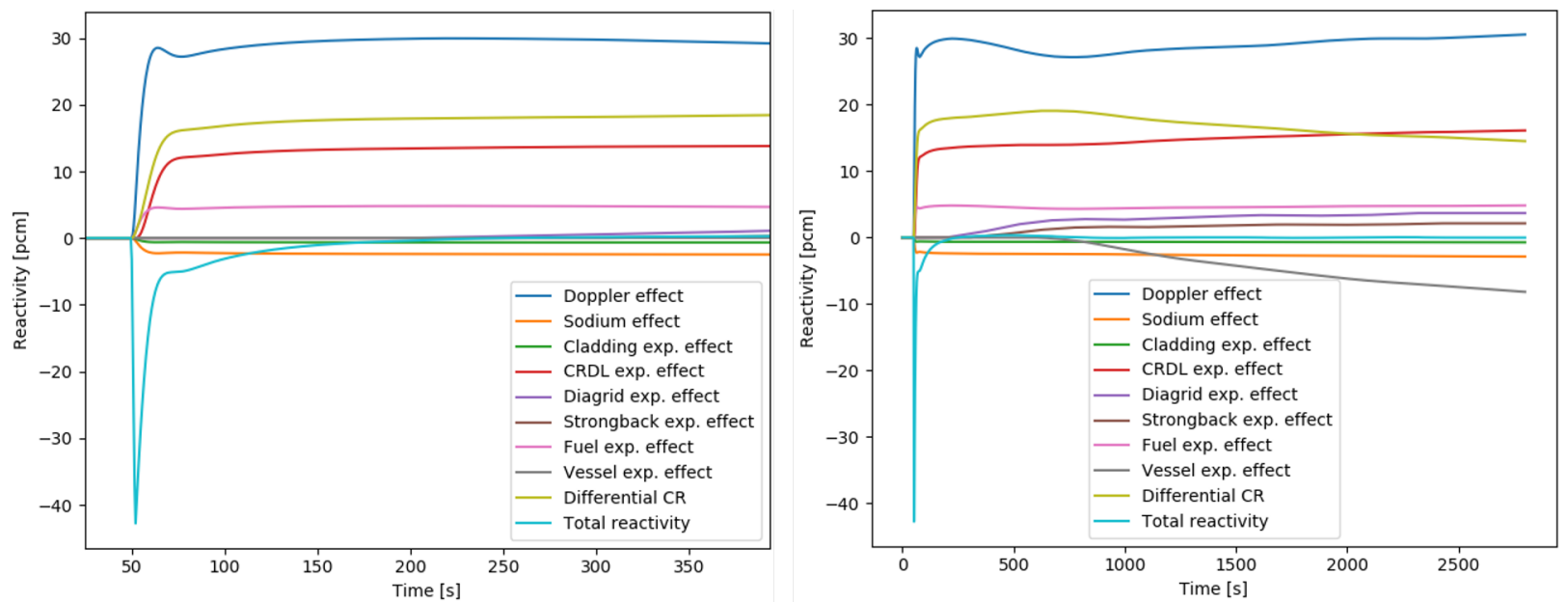

Figure 5: Reactivity components calculated by the point kinetic model during the MOCF1 transient. Left side: zoom on the beginning of the transient.

\section{CONCLUSION}

Detailed modelling of core expansion effects is mandatory for sodium cooled fast reactors. In this paper, the 3-D radial core expansion model implemented in PARCS by GRS was applied to the Superphénix neutronic benchmark. An ATHLET parallel channel open core model has been developed and axial thermal expansion of the structure influencing the relative position of the control rod in the active core is modelled. The coupling interface is extended to allow for the transfer of diagrid temperature to PARCS. 
The analysed transient is initiated by inserting $-50 \mathrm{pcm}$ of reactivity in $2 \mathrm{~s}$. A point kinetic simulation is also performed to compare with the 3D neutron kinetic solution. Both ATHLET-point kinetic model and ATHLET-PARCS simulations deliver a similar power evolution during the transient but with constant power offset. By analysing the different feedback in the point kinetic model, it can be concluded that models of radial core expansion and the axial expansion of the different structures (fuel rod, strongback, vessel, CRDL) influencing the relative position of the control rod in the active core are well implemented. Future work includes on the one hand, further investigation of the observed offset between the 3D and the point kinetics models, and on the other hand, analysis of additional transients of the benchmark.

\section{REFERENCES}

[1] J. Gourdon et al. "An Overview of Superphénix Commissioning Tests." Nuclear Science and Engineering, volume 106, pp. 1-10 (1990).

[2] K. Mikityuk et al. "ESFR-SMART: new Horizon-2020 project on SFR safety." In Proceedings of the Intl. Conf. on Fast Reactors and Related Fuel Cycles (FR17). Yekaterinburg, Russian Federation, June 26-29, 2017 (2017).

[3] A. Ponomarev, A. Bednarova, and K. Mikityuk. "New sodium fast reactor neutronics benchmark." In Proceedings of the Intl. Conf. PHYSOR 2018, pp. 3790-3804. Cancun, Mexico, April 22-26, 2018 (2018).

[4] T. Downar et al. "PARCS: Purdue Advanced Reactor Core Simulator." In Proceedings of the Intl. Conf. PHYSOR 2002. Seoul, Korea, October 7-10, 2002 (2002).

[5] A. Seubert and K. Velkov. "Fast Reactor Diagrid and Axial Expansion Models for the Diffusion Equation." In Proceedings of the Intl. Conf. PHYSOR 2016. Sun Valley, ID, USA, May $1-5,2016$ (2016).

[6] J. Bousquet, A. Seubert and P. Sarkadi. "3-D Coupled PARCS/ATHLET simulation of SFR using explicit radial expansion model." In Proceedings of the Intl. Conf. PHYSOR 2018. Cancun, Mexico, April 22-26, 2018 (2018).

[7] J. Leppänen et al. "The Serpent Monte Carlo code: Status, development and applications in 2013." Annals of Nuclear Energy, volume 82, pp. 142-150 (2015).

[8] R. Henry and A. Seubert. "3-D modelling of a Superphénix benchmark with Serpent and PARCS for coupled simulation with PARCS/ATHLET." In Proceedings of the Intl. Conf. $M \& C$ 2019. Portland, OR, USA, August 25-29, 2019 (2019).

[9] H. Austregesilo et al. "ATHLET 3.2 Models and Methods." Technical Report GRS-P-1/Vol. 3, Rev. 5, Gesellschaft für Anlagen- und Reaktorsicherheit (GRS) gGmbH (2019).

[10] M. Zilly and Y. Périn. "KMACS Validation Report.” Technical Report GRS-P-8/Vol. 2, Rev. 0, Gesellschaft für Anlagen- und Reaktorsicherheit (GRS) gGmbH (2018).

[11] A. E. Waltar, D. R. Todd, and P. V. Tsvetkov. Fast Spectrum Reactors. Springer Science+Business Media LLC, Boston, MA (2012).

[12] A. Schaffrath, A. Wielenberg, M. Sonnenkalb and R. Kilger. "The nuclear simulation chain of GRS and its improvements for new ALWR and SMR typical phenomena." In Proceedings of the Intl. Conf. NUTHOS-12. Qingdao, China, October 14-18, 2018 (2018).

[13] K. Mikityuka and M. Schikorrb. "New transient analysis of the Superphénix start-up tests." In Proceedings of the Intl. Conf. FR13. Paris, France, March 4-7, 2013 (2013). 